\title{
Retention of Anticancer Activity of Curcumin after Conjugation with Fluorescent Gold Quantum Clusters: An in Vitro and in Vivo Xenograft Study
}

Puneet Khandelwal, ${ }^{\dagger}$ Aftab Alam, ${ }^{\ddagger}$ Arpankumar Choksi, ${ }^{\ddagger}$ Samit Chattopadhyay, ${ }^{\S}$ and Pankaj Poddar ${ }^{*}, \dagger$

${ }^{\dagger}$ Physical \& Materials Chemistry Division, CSIR-National Chemical Laboratory, Pune 411008, India

${ }^{\ddagger}$ National Center for Cell Science, Ganeshkhind, Pune 411 007, India

${ }^{\S}$ CSIR-Indian Institute of Chemical Biology, 4, Raja S.C. Mullick Road, Kolkata 700 032, India

\section{Supporting Information}

\begin{abstract}
Gold nanoparticles (Au NPs) have been thoroughly investigated for anti-cancer therapy. However, their undesired high gold content remains a problem when injected into the body for drug delivery applications. In this report, we made an effort to conjugate the curcumin molecules on the surface of gold quantum clusters (Au QCs) by a novel in situ synthesis method which provides an alternative route to not only reduce the metallic content but also increase the water solubility of curcumin and the loading efficiency. Here, curcumin itself acts as a reducing and capping agent for the synthesis of $\mathrm{Au}$ QCs. The UV-vis absorption, fluorescence, transmission electron microscopy, and electrospray ionization mass spectrometry results confirmed the synthesis of fluorescent $\mathrm{Au}$ QCs. Curcumin-conjugated Au NPs (C-Au NPs) and glutathione (GSH)conjugated $\mathrm{Au}$ QCs (GSH-Au QCs) were also synthesized to visualize the effect of particle size and the capping agent, respectively, on the cytotoxicity
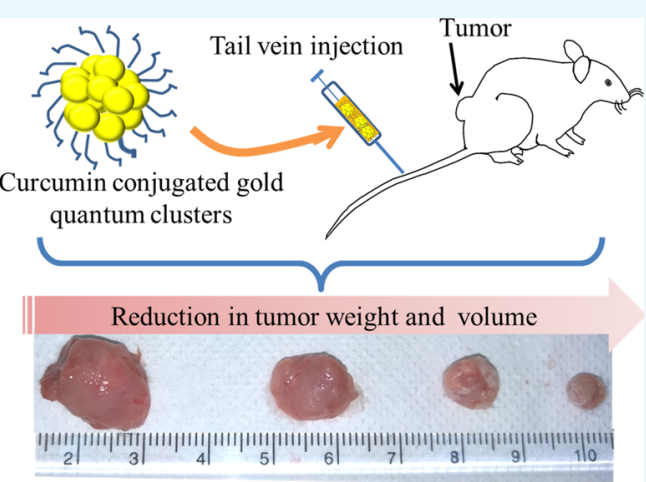
to normal and cancer cells. The 3-(4,5-dimethylthiazol-2-yl)-2,5-diphenyltetrazolium bromide assay showed that the curcuminconjugated Au QCs (C-Au QCs) were less cytotoxic to normal cells while almost the same cytotoxic to cancer cells in comparison to curcumin itself, which indicates that curcumin preserves its anticancer property even after binding to the Au QCs. However, C-Au NPs and GSH-Au QCs did not show any cytotoxicity against the normal and cancer cells at the concentration used. The western blot assay indicated that $\mathrm{C}-\mathrm{Au}$ QCs promote apoptosis in cancer cells. Further, the in vivo study on severe combined immunodeficiency mice showed that C-Au QCs also inhibited the tumor growth efficiently without showing significant toxicity to internal organs.
\end{abstract}

\section{INTRODUCTION}

Curcumin (1,7-bis(4-hydroxy-3-methoxyphenyl)-1,6-heptadiene-3,5-dione) is a polyphenol and the main functional component of turmeric derived from the rhizome of a medicinal plant- "Curcuma longa". ${ }^{1}$ Curcumin has been used as the main ingredient of Indian spices and traditional ayurvedic medicines since ancient times in the Asian countries. ${ }^{2}$ Curcumin has attracted enormous attention because of its wide range of pharmacological applications such as antioxidant, antiangiogenic, antimicrobial, anti-inflammatory, anticancer, anti-Alzheimer, antiparasitic, antiviral, and so forth. ${ }^{1,3-30}$ Earlier studies show that curcumin has chemopreventive activity against several types of cancers such as prostate, breast, and colorectal cancer. ${ }^{15,31,32}$ The molecular basis of chemopreventive activity of curcumin is its effect on several targets such as transcription factors (NF- $\kappa \mathrm{B})$, growth targets, apoptotic genes ( $\mathrm{p} 53, \mathrm{Bcl}-2)$, angiogenesis regulators, and cell signaling genes (TNF- $\alpha)$.,15

Despite numerous biological activities, curcumin could not be used efficiently for therapeutic applications because of its poor systemic bioavailability originating from low water solubility and instability. ${ }^{2}$ To overcome the problem of water solubility of curcumin, researchers have tried to make various formulations such as encapsulation in polymeric nanoparticles, silica nanoparticles, lipid micelles, metal nanoparticles, microemulsions, and the preparation of curcumin analogues. ${ }^{17,32-35}$

Although, the complexation of curcumin with metal nanoparticles [especially with gold nanoparticles (Au NPs)] has been used in many reports because of their low toxicity and biocompatible nature, gold quantum clusters ( $\mathrm{Au}$ QCs) made up of few to few tens of atoms may also be used as an alternative because of their small size and interesting physical properties. ${ }^{1,19,36-43}$ In our previous study, we observed in the density functional theory calculations that upon conjugation of curcumin molecules with gold, the intramolecular hydrogen bond distance increased, which facilitates the formation of

Received: January 19, 2018

Accepted: April 23, 2018

Published: May 1, 2018 
Scheme 1. Schematic Representation of the Curcumin Structure and the Synthesis of C-Au QCs ${ }^{a}$

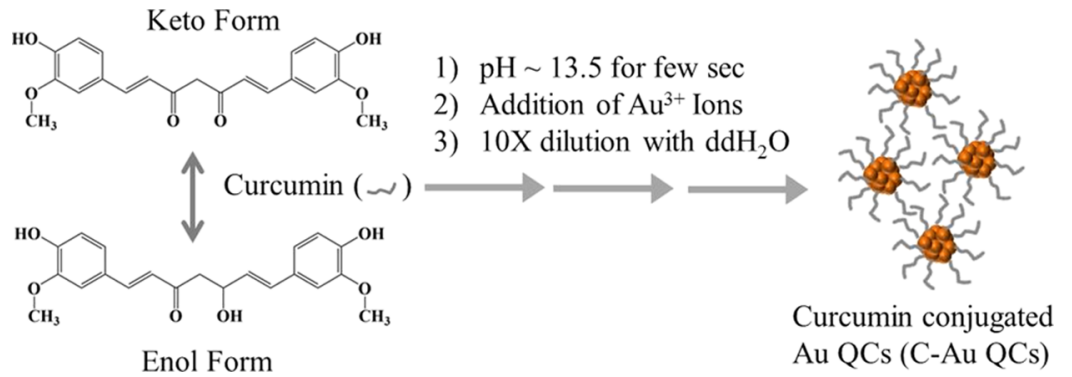

${ }^{a}$ Curcumin is a tautomeric compound present in two forms, namely, keto and enol form.

hydrogen bonding of curcumin molecules with the adjacent water molecules and hence increases the water dispersibility of curcumin-conjugated $\mathrm{Au}$ NPs. ${ }^{1} \mathrm{Au}$ QCs show the discrete energy of states resulting in the tunable emission of light from UV to near-infrared (NIR) region. ${ }^{43-46}$ In the last decade, $\mathrm{Au}$ QCs acquired extremely high attention because of their numerous benefits such as: (a) they are nontoxic to the mammalian cells; (b) their size is smaller than the biomolecules of interest. Therefore, they are unlikely to interfere in the normal biological functions such as biomolecular interactions; (c) they possess optimal photophysical properties including low photobleaching, absence of blinking, large Stokes shift, high water dispersibility, and high quantum yield; (d) NIR fluorescence; (e) they can act as an effective radiosensitizer; and, finally, (f) they easy to synthesize and use for labeling biomolecules. ${ }^{43} \mathrm{Au}$ QCs have been used extensively for in vitro and in vivo bioimaging, sensing, drug delivery, photodynamic therapy, catalysis, and so forth. ${ }^{43,47-56}$

$\mathrm{Au}$ QCs have been used for cancer therapy in many studies by several groups. Huang et al. reported the use of photosensitizer-conjugated silica-coated Au QCs for fluorescence imaging-guided photodynamic therapy. ${ }^{57}$ Nair et al. designed a biocompatible Au QC-based multifunctional system for fluorescence imaging-directed photodynamic therapy, which is useful for efficient destruction and monitoring of tumor cells. $^{49}$ Zhang et al. used epidermal growth factor receptorconjugated $\mathrm{Au}$ QCs for targeted cancer radiation treatment. ${ }^{58}$ Khandelia et al. developed Au QC-embedded albumin nanoparticles as a doxorubicin drug delivery vehicle for anticancer applications. ${ }^{59}$ Zhou et al. demonstrated the synthesis of cisplatin-conjugated $\mathrm{Au}$ QCs for fluorescence imaging and targeted therapy of breast cancer. ${ }^{60}$ Recently, Chen et al. developed arginylglycylaspartic acid- and aptamerconjugated dual-targeting Au QCs bounded with doxorubicin for tumor imaging and deep tissue therapy. ${ }^{61}$

There are several reports in which the biologically active protein molecules have been used for the synthesis of Au QCs where they act as a reducing and capping agent and also able to retain their biological activity. For example, Chen et al. synthesized lysozyme-protected Au QCs which exhibited potential superior antimicrobial activity. ${ }^{62}$ Liu et al. reported insulin-directed synthesis of $\mathrm{Au}$ QCs which were shown to retain the insulin bioactivity. ${ }^{63}$ Nair et al. developed NIRemitting urease-conjugated $\mathrm{Au}$ QCs for the highly selective sensing of urea in the whole blood samples. ${ }^{64}$ However, there are very few reports where small molecules used to synthesize $\mathrm{Au}$ QCs and able to retain their biological activity as well. In this report, curcumin molecules were utilized for the synthesis of $\mathrm{Au} \mathrm{QCs}$ as a reducing and capping agent and found to preserve their anticancer activity with low cytotoxicity to normal mammalian cells in comparison to curcumin alone. No other reducing agents (except curcumin) were used in the synthesis of $\mathrm{Au}$ QCs.

\section{RESULTS AND DISCUSSION}

Synthesis of Curcumin-Conjugated Au QCs. The synthesis of $\mathrm{Au}$ QCs using curcumin as both a reducing and capping agent is very crucial regarding the solubility of curcumin. Curcumin exists in the planar intramolecularly hydrogen-bonded form. It has a hydrophobic nature because of the lack of polar groups in the aqueous medium at neutral $\mathrm{pH}$ and the stretch of conjugated heptadiene backbone (Scheme 1$).{ }^{27}$ Curcumin is soluble in water only at the alkaline condition, but at the same time, it also shows degradation. According to Price and Buescher, the degradation rate constant rapidly increases from $\mathrm{pH} \approx 7.4$ to a maximum at $\mathrm{pH} \approx 10.2$ and then declines at higher $\mathrm{pH}$ values. ${ }^{26}$ Therefore, instead of low $\mathrm{pH}$ where the curcumin molecules also have low solubility, a high $\mathrm{pH} \approx 13.5$ was selected for the reaction where curcumin molecules were completely soluble and the degradation rate constant was also small.

The UV-vis spectroscopic study of curcumin in dimethyl sulfoxide (DMSO) and the alkaline medium shows two distinct absorption bands at $\sim 262$ and $\sim 425 \mathrm{~nm}$, which are related to the $\mathrm{n}-\pi^{*}$ and $\pi-\pi^{*}$ transitions, respectively (Figure 1a). ${ }^{1,27}$ It can be seen from Figure 1a that the transition at $\sim 262 \mathrm{~nm}$ was least affected when conjugated with Au NPs and Au QCs. The UV-vis spectrum of C-Au NPs shows a sharp peak in deep UV at $\sim 262 \mathrm{~nm}$ because of the $\mathrm{n}-\pi^{*}$ transition of curcumin molecules and a broad peak in the visible region at $\sim 528 \mathrm{~nm}$ because of the surface plasmon resonance (SPR). Interestingly, in the case of C-Au QCs and glutathione (GSH)-Au QCs, the SPR peak was diminished, which shows the absence of Au NPs in the suspension (Figure 1a).

The photoluminescence study of curcumin shows the emission at $\sim 545 \mathrm{~nm}$ at an excitation of $\sim 425 \mathrm{~nm}$ wavelength in the alkaline medium (Figure S2). On the other hand, C-Au QCs show the maximum intense emission peak $\sim 470 \mathrm{~nm}$ when excited with the $\sim 360 \mathrm{~nm}$ wavelength of light (Figure 1b), whereas C-Au NPs did not show fluorescence at any excitation wavelength because of the quenching by nonradiative decay available in Au NPs (Figure S3). However, GSH-Au QCs show photoluminescence at $\sim 800 \mathrm{~nm}$ when excited with $\sim 450 \mathrm{~nm}$ wavelength of light (Figure S4).

Transmission electron microscopy (TEM) images of C-Au QCs and GSH-Au QCs indicate the presence of ultrasmall particles with an average size $\sim 2 \mathrm{~nm}$. The particles were welldispersed and uniform in size (Figure 2). C-Au NPs were also 


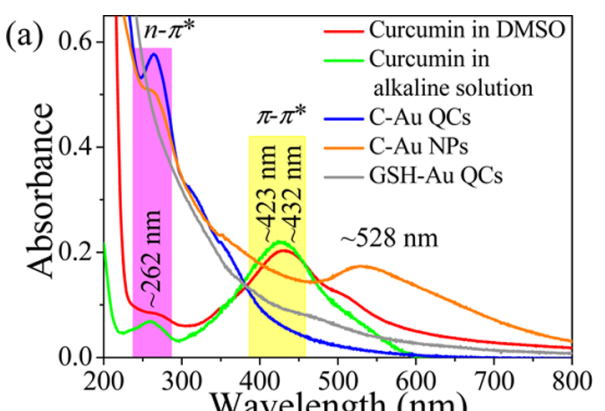

(b)

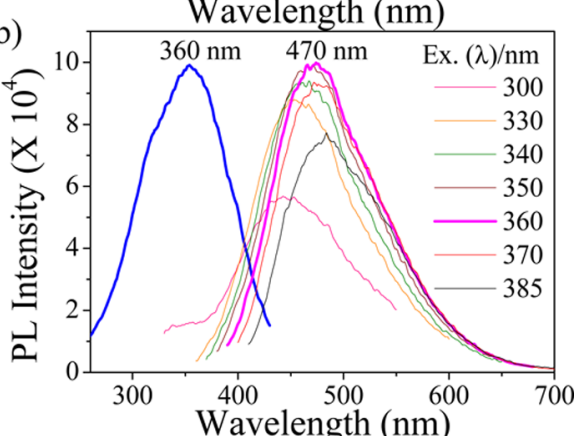

Figure 1. (a) UV-vis spectroscopic study of curcumin in DMSO and alkaline conditions; C-Au QCs, C-Au NPs, and GSH-Au QCs. (b) Photoluminescence spectra of C-Au QCs upon excitation with light of different wavelengths.

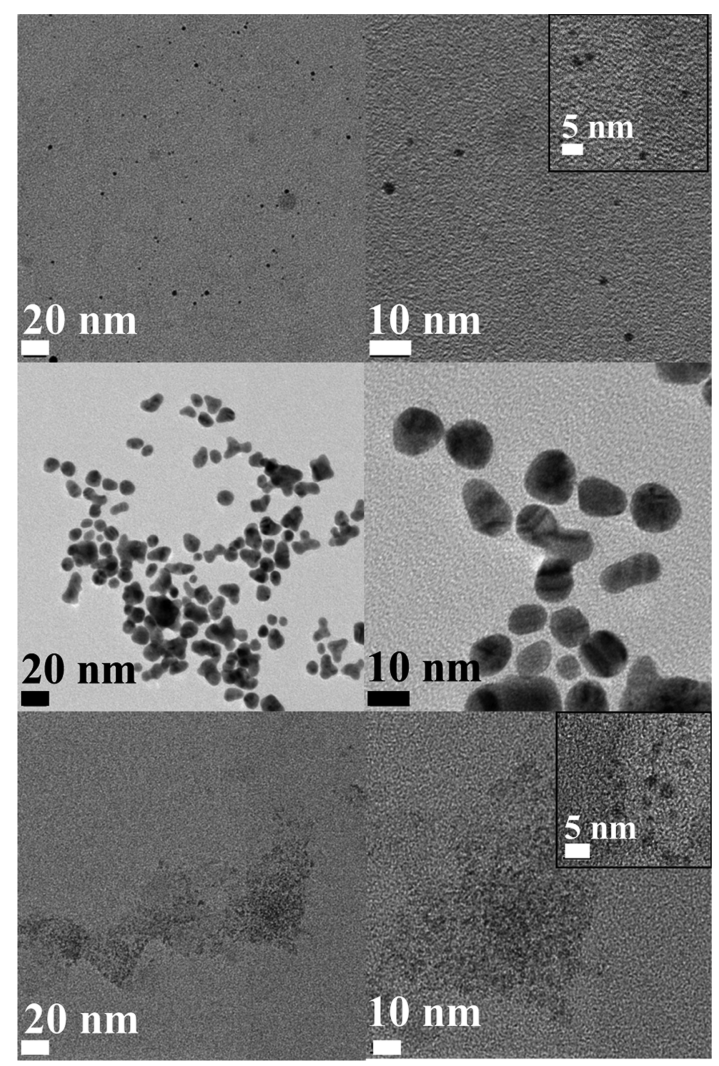

Figure 2. TEM images of C-Au QCs (top layer), C-Au NPs (middle layer), and GSH-Au QCs (bottom layer). The inset images are respective magnified images.

very well-dispersed with an average size $\sim 15 \mathrm{~nm}$. Dynamic light scattering (DLS) measurements were carried out to confirm the size distribution of as-synthesized $\mathrm{Au}$ QCs and $\mathrm{Au}$ NPs after dialysis. The DLS results correlated well with the particle size measured by TEM analysis, considering the various contributions to the hydrodynamic diameter. The mean hydrodynamic diameters of C-Au QCs, GSH-Au QCs, and C-Au NPs were found to be $\sim 4.5, \sim 2.3$, and $\sim 20.2 \mathrm{~nm}$, respectively (Figures S5-S7). The larger hydrodynamic diameter of C-Au QCs in comparison to the GSH-Au QCs might be due to the little aggregation of $\mathrm{C}-\mathrm{Au} \mathrm{QCs}$ in the aqueous medium. Furthermore, DLS measurements were also conducted to analyze the size distribution of $\mathrm{C}$-Au QCs in fetal bovine serum (FBS) containing cell culture media. There was no significant aggregation noticed even after the incubation of C-Au QCs with the media for 1 day (Figure S8).

To understand the binding behavior of curcumin to the Au QCs, Fourier transform infrared (FTIR) study was performed (Figure 3). Curcumin molecules showed three bands at 1375,

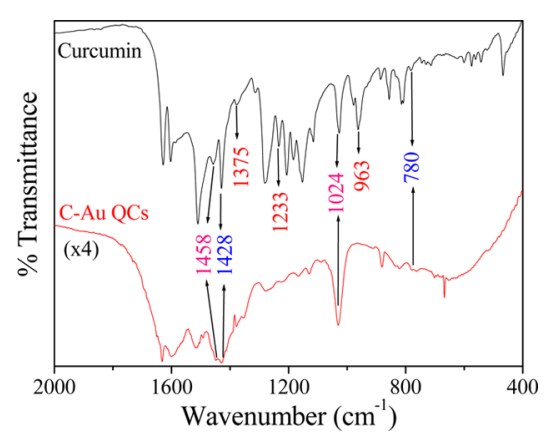

Figure 3. FTIR spectra of curcumin (black color) and C-Au QCs (red color). The spectrum for $\mathrm{C}-\mathrm{Au} \mathrm{QCs}$ was multiplied by four to make all peaks clearly visible.

1233, and $963 \mathrm{~cm}^{-1}$ (indicated with red color fonts in Figure 3 ), which are due to the in-plane bending vibrations of the hydroxyl group of the two phenolic groups and an enolic group, respectively. All of these three bands were not observed in the case of C-Au QCs, which shows the interaction of $\mathrm{Au}$ at these sites, whereas the presence of two bands at 780 and $1428 \mathrm{~cm}^{-1}$ (indicated with blue color fonts) in the spectrum of C-Au QCs related to the olefinic in-plane bending vibrations of the heptadiene chain of curcumin confirm the presence of intact curcumin after the C-Au QCs synthesis. ${ }^{40}$ Similarly, the two bands present in the spectra of both curcumin and C-Au QCs at 1458 and $1024 \mathrm{~cm}^{-1}$ (indicated with pink color fonts) are due to the mixed vibration of $\mathrm{CH}_{3}$ and aromatic $-\mathrm{C}=\mathrm{C}-\mathrm{C}$, respectively, which confirmed the presence of curcumin as a capping agent. ${ }^{65}$

Further, X-ray photoelectron spectroscopy (XPS) study was also performed to analyze the functional groups of curcumin involved in binding with C-Au QCs (Figure 4). The XPS measurements were carried out for the core-level electrons of carbon, oxygen, and gold atoms. The XPS spectra of carbon (C $1 s$ ) for curcumin can be deconvoluted in four peaks situated at $284.5,285,286.3$, and 287.3, corresponding to $\mathrm{sp}^{2}$ carbon, $\mathrm{sp}^{3}$ carbon, $\mathrm{C}-\mathrm{O}$, and $\mathrm{C}=\mathrm{O}$, respectively. Most of the peaks for $\mathrm{C}$ $1 s$ spectra of C-Au QCs were also deconvoluted in four peaks almost at the same place like curcumin, except the peak for $\mathrm{C}=$ $\mathrm{O}$, which was located at $286.7 \mathrm{eV}$. Therefore, the peak for $\mathrm{C}=$ $\mathrm{O}$ was found to be downshifted by around $0.4 \mathrm{eV}$, which shows the involvement of the $\mathrm{C}=\mathrm{O}$ moiety in the binding of curcumin to the Au QC surface. The XPS spectra of oxygen (O 1s) for curcumin was deconvoluted in two peaks situated at 532.1 and $533.5 \mathrm{eV}$ related to $\mathrm{C}-\mathrm{O}$ and $\mathrm{C}=\mathrm{O}$, respectively. 

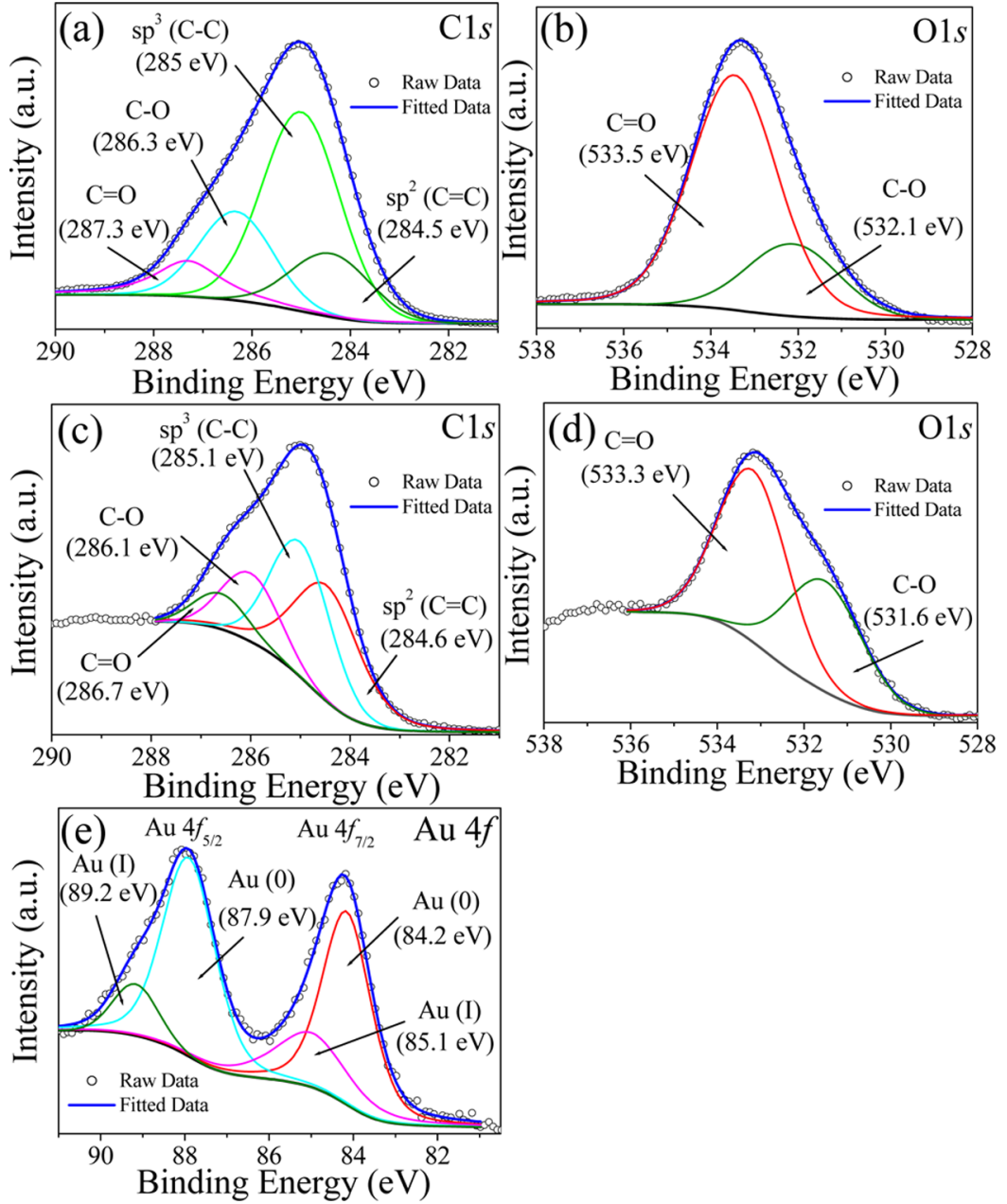

Figure 4. Deconvoluted XPS spectra of ( $a, b)$ curcumin and ( $c-e)$ C-Au QCs. XPS spectra a and $c$ represent the C $1 s$ core-level electrons, whereas b and $\mathrm{d}$ represent the $\mathrm{O} 1 s$ core-level electrons and e represents the $\mathrm{Au} 4 \mathrm{f}$ core-level electrons.

One of these two peaks related to $\mathrm{C}-\mathrm{O}$ for $\mathrm{C}-\mathrm{Au} \mathrm{QCs}$ also got downshifted by 0.5 to $531.6 \mathrm{eV}$. This shows that oxygen atoms of $\mathrm{C}=\mathrm{O}$ and $\mathrm{C}-\mathrm{O}$ of curcumin molecules are involved in the binding to the Au QC surface. The XPS spectrum for Au $4 f$ showed two broad peaks corresponding to $\mathrm{Au} 4 f_{7 / 2}$ and $\mathrm{Au}$ $4 f_{5 / 2}$ (Figure 4). The deconvolution of these peaks indicated the presence of $\mathrm{Au}$ in two oxidation states: (a) $\mathrm{Au}(0)$ and (b) $\mathrm{Au}(\mathrm{I})$. Au $4 f_{7 / 2}$ can be deconvoluted in two peaks situated at $\sim 83.7$ and $\sim 84.6 \mathrm{eV}$ related to the presence of $\mathrm{Au}(0)$ and $\mathrm{Au}(\mathrm{I})$ oxidation states, respectively, whereas the $\mathrm{Au} 4 f_{5 / 2}$ peak was deconvoluted in two peaks located at $\sim 87$ and $\sim 88 \mathrm{eV}$, associated with the presence of $\mathrm{Au}(0)$ and $\mathrm{Au}(\mathrm{I})$ oxidation state, respectively (Figure 4). ${ }^{66,67}$

To determine the composition of C-Au QCs, electrospray ionization mass spectrometry (ESI-MS) analysis was performed. Most of the peaks in the deconvoluted ESI-MS spectrum for C-Au QCs were found in between 2000 and 8000 $\mathrm{Da}$. The spectrum shows many peaks, which may be due to the synthesis of a mixed population of Au QCs (Figure S9). The ESI-MS measurement was also performed for curcumin molecules to confirm their integrity and the mass peak distribution profile (Figure S10). It was observed that most of the peaks for curcumin molecules were in the region from 100 to $1400 \mathrm{Da}$, which shows that curcumin molecules do not have any contribution to the spectrum of C-Au QCs. However, there are many other peaks in the ESI-MS spectra of both curcumin and C-Au QCs which could not be assigned because of the degradation of a small fraction of curcumin molecules.

In Vitro Cytotoxicity to Normal and Cancer Cells. To determine the cytotoxic effect of curcumin, C-Au QCs, GSH$\mathrm{Au}$ QCs, and C-Au NPs, 3-(4,5-dimethylthiazol-2-yl)-2,5diphenyltetrazolium bromide (MTT) assay was performed against the normal (NIH 3T3) and cancer (MCF7) cell lines. For these experiments, the $\mathrm{C}-\mathrm{Au} \mathrm{QCs}$ concentration was decided based on the amount of curcumin molecules loaded on the C-Au QCs which was determined using UV-vis absorption measurements (described in Experimental section). C-Au NPs and GSH-Au QCs were synthesized to investigate the role of particle size and surface ligands on the cell cytotoxicity, respectively. For the sake of fare comparison, the concentration of C-Au NPs and GSH-Au QCs was selected based on the Au content present in the C-Au QC sample, which was determined by inductively coupled plasma-optical emission spectrometry (ICP-OES).

The samples at different concentrations were incubated with $\mathrm{NIH} 3 \mathrm{~T} 3$ and MCF7 cells for $24 \mathrm{~h}$ at $37{ }^{\circ} \mathrm{C}$. The equivalent amount of free curcumin molecules was found to be more cytotoxic to normal cells than $\mathrm{C}$-Au QCs at the concentration of $25 \mu \mathrm{g} / \mathrm{mL}$ (Figure 5a,b). Interestingly, the cytotoxicity of C$\mathrm{Au}$ QCs to MCF7 cells was almost the same as curcumin up to the concentration of $25 \mu \mathrm{g} / \mathrm{mL}$ (Figure $5 \mathrm{c}, \mathrm{d}$ ). Figure 5e shows the clear difference between the cell viability of normal and 

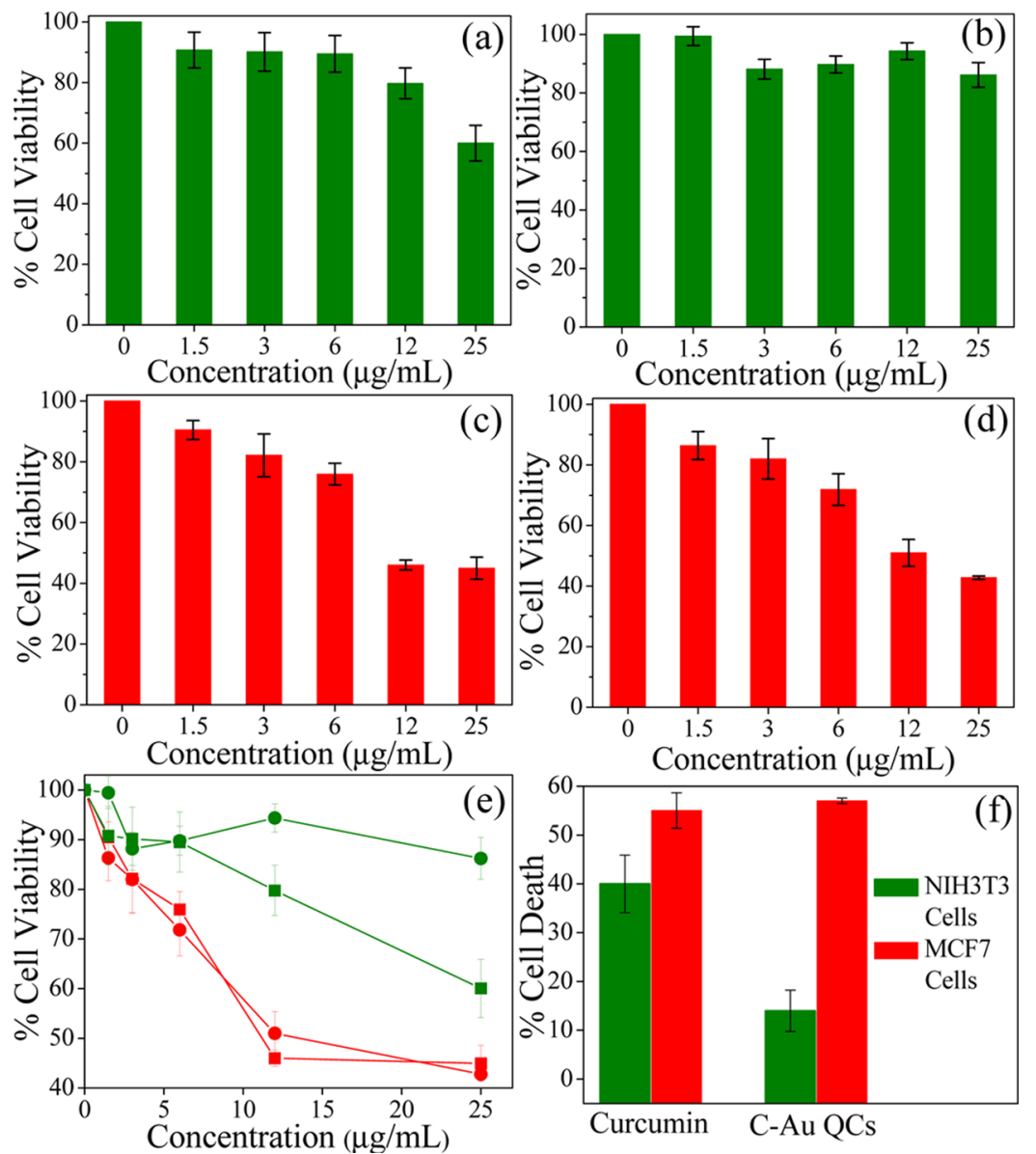

Figure 5. In vitro normal (NIH3T3) and cancer (MCF7) cell viabilities after incubation of $24 \mathrm{~h}$ with curcumin (a,c) and C-Au QCs (b,d). (e)

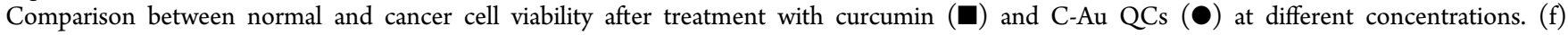
Comparison between normal and cancer cell death after treatment with curcumin and C-Au QCs at the curcumin concentration of $25 \mu \mathrm{g} / \mathrm{mL}$. The normal and cancer cells were represented with green and red color, respectively.
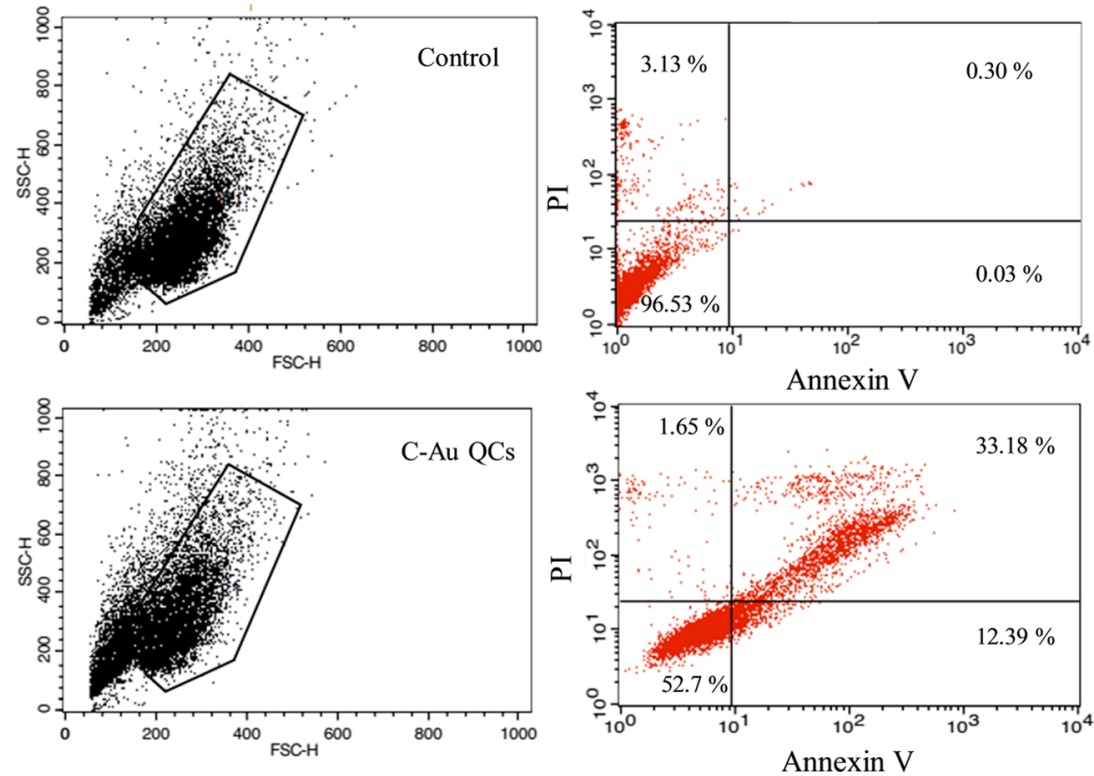

Figure 6. Flow cytometric analysis of MCF7 cells without (top layer) and with C-Au QC treatment (bottom layer).

cancer cells after the treatment with curcumin and C-Au QCs at different concentrations. It can be easily seen from Figure $5 \mathrm{f}$ that curcumin shows $\sim 40$ and $\sim 55 \%$ cell death in comparison to C-Au QCs $\sim 14$ and $\sim 57 \%$ for normal and cancer cells, respectively, at the concentration of $25 \mu \mathrm{g} / \mathrm{mL}$. These results indicate that curcumin is able to retain its anticancer property 
with lesser normal cell cytotoxicity even after conjugation with $\mathrm{Au}$ QCs. The probable reason behind the differential cytotoxicity of C-Au QCs to the cancer cells may be due to the high metabolism rate of cancer cells in comparison to normal cells, which leads to the higher uptake of C-Au QCs to the cancer cells.

$\mathrm{C}-\mathrm{Au}$ NPs and GSH-Au QCs were found to be the almost noncytotoxic to both the normal and cancer cells at the $\mathrm{Au}$ concentrations used (Figure S11). C-Au NPs did not show cytotoxicity to the cancer cells; this may be due to the fewer numbers of $\mathrm{Au}$ NPs present in the sample, which also reduces the number of curcumin molecules in comparison to $\mathrm{C}-\mathrm{Au}$ QCs, for the same amount of $\mathrm{Au}$ present in the sample. However, GSH-Au QCs did not show the cytotoxicity to both normal and cancer cells may be due to the biocompatible nature of GSH.

Mechanism behind the Cytotoxicity of C-Au QCs to the Cancer Cells. To further determine the mechanism behind the cytotoxic effect of C-Au QCs to the cancer cells, annexin $\mathrm{V}$ and propidium iodide (PI) staining was done. The PI and annexin V-fluorescein isothiocyanate (FITC) doublepositive cells show the apoptotic cells out of the total cells analyzed by flow cytometry. The results revealed that MCF7 cells treated with $\mathrm{C}$-Au QCs showed $\sim 33.2 \%$ apoptotic and $12.4 \%$ preapoptotic population. In total, almost around $50 \%$ of $\mathrm{C}-\mathrm{Au} \mathrm{QC}$-treated cells have undergone the apoptotic process leading to cell death (Figure 6).

Later, western blot experiment for the C-Au QC-treated MCF7 cells was carried out to evaluate the effect of C-Au QCs on the expression of proapoptotic and antiapoptotic markers. The C-Au QC treatment resulted in the increased expression of the proapoptotic protein such as cleaved poly(ADP-ribose) polymerase (PARP) compared to the control cells (Figure 7).

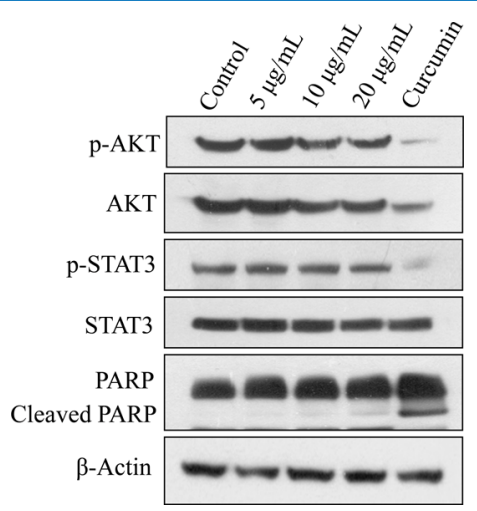

Figure 7. Western blot analysis of survival and proapototic proteins in breast cancer MCF7 cells upon treatment with C-Au QCs. Curcumin was used as the positive control and $\beta$-actin was used as the loading control.

The presence of cleaved PARP in the C-Au QC-treated cancer cells directly correlates with the induction of apoptosis. ${ }^{31}$ Also, the expression of antiapoptotic proteins, such as phosphor-AKT and phosphor-STAT3, was significantly decreased in the treated cells compared to the control cells, indicating that C-Au QCs induce apoptosis in the cancer cells (Figure 7).

In Vivo Anticancer Study on the Murine Xenograft Model. Because C-Au QCs inhibited the growth of MCF7 breast cancer cells in vitro, it was stimulating to perform in vivo study using a murine xenograft model to evaluate the inhibitory effect of C-Au QCs on tumor growth. One week after the $1 \times$
$10^{6}$ MDA-MB 231 breast cancer cells were injected subcutaneously into the flank areas of BALB/c SCID mice, $\mathrm{C}-\mathrm{Au}$ QCs were injected intraperitoneally at a dosage of 20 $\mathrm{mg} / \mathrm{kg}$ thrice a week. Four weeks after the injection of MDAMB 231 breast cancer cells, tumor size, tumor volume, and tumor weight decreased significantly in the group treated with $\mathrm{C}-\mathrm{Au}$ QCs when compared to the control group (Figure 8).

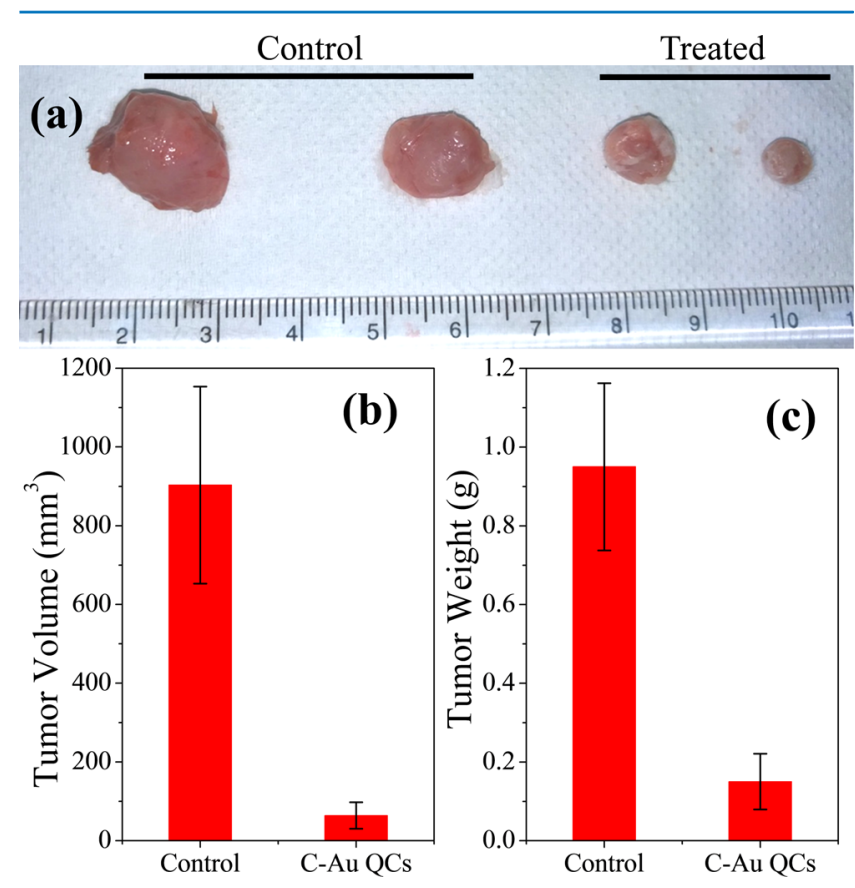

Figure 8. C-Au QCs inhibit tumor growth in xenografts of MDA-MB 231 breast cancer cells. (a) Size of MDA-MB 231 tumors; the mice were sacrificed on day 30 and tumors were resected. (b) Tumor volume before (control) and after the treatment with $20 \mathrm{mg} / \mathrm{kg} \mathrm{C}-\mathrm{Au}$ QCs. Tumor volume $\left(\mathrm{mm}^{3}\right)$ after 30 days of treatment is shown. Data represent the average of tumor volume. (c) Tumor weight after 30 days of C-Au QCs treatment.

Most of the chemotherapeutic drugs result in tissue damage in the vital organs, which leads to the deterioration of the patient health. Therefore, histopathological analysis was carried out for different organs dissected from mice after 4 weeks of C$\mathrm{Au}$ QC injections post MDA-MB 231 tumor inoculation (Figure 9). The liver tissue sections from the C-Au QC-treated mice showed a normal liver architecture, with well-preserved hepatocytes. In addition, the tissue architecture and morphology of the mice liver tissue section from the C-Au QC-treated mice were similar to the control group. The lung sections from the control and C-Au QC-treated samples were examined for alveolar congestion and intra-alveolar hemorrhage to check their toxicity. No significant toxicity was observed in the treated samples, and the morphology was almost similar to the control group. Similarly, kidney and heart sections were analyzed for interstitial edema and tissue damage in the control and C-Au QC-treated samples. No pathological changes were observed in the $\mathrm{C}-\mathrm{Au} \mathrm{QC}$-treated mice compared to the control. These results suggest that $\mathrm{C}-\mathrm{Au} \mathrm{QCs}$ do not show toxicity to the vital organs of mice.

\section{CONCLUSIONS}

In summary, we synthesized C-Au QCs which have small size and high curcumin loading capacity than their counterparts, 


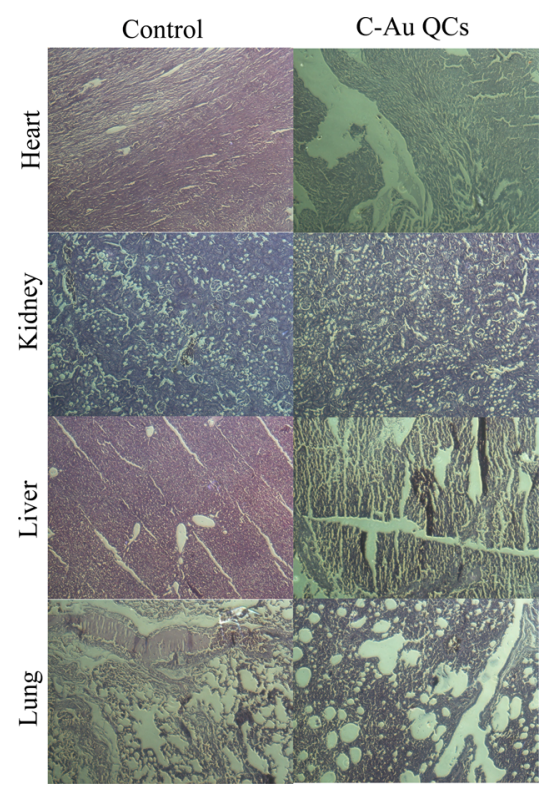

Figure 9. Internal organs of mice treated with $\mathrm{C}-\mathrm{Au} \mathrm{QCs}$ in the murine xenograft model. After the mice were sacrificed on day 30 , the liver, lung, heart, and kidney were resected, fixed, and embedded in paraffin. The samples were sliced to $5 \mu \mathrm{m}$ in thickness and stained with hematoxylin and eosin dyes (magnification 10×).

that is, C-Au NPs, for the same amount of gold content. Curcumin molecules, even after conjugation to Au QCs, were observed to retain their cytotoxicity to cancer cells while showing less cytotoxicity to the normal cells in comparison to curcumin alone. Flow cytometry and western blot assay confirm that $\mathrm{C}-\mathrm{Au} \mathrm{QCs}$ induce apoptosis in cancer cells. Further, in vivo study showed that C-Au QCs were able to effectively decrease the tumor size without producing any significant toxicity to the internal organs. Therefore, we believe that C-Au QCs can be a promising candidate for anticancer therapy because of their small size, high drug loading capacity, low gold content, and low cytotoxicity.

\section{EXPERIMENTAL SECTION}

Materials. All chemicals were of analytical grade and used as-received without any further purification unless otherwise mentioned. The benzoylated dialysis tube, curcumin, $\mathrm{HAuCl}_{4}$. $3 \mathrm{H}_{2} \mathrm{O}$, and DMSO were purchased from Sigma-Aldrich. Sodium hydroxide $(\mathrm{NaOH})$ was purchased from Thomas Baker. All glassware were washed with aquaregia $\left(\mathrm{HCl} / \mathrm{HNO}_{3}\right.$ $=3: 1)$ carefully and rinsed with double distilled water $\left(\mathrm{ddH}_{2} \mathrm{O}\right)$ before using them for synthesis.

Synthesis of Curcumin-Conjugated Au QCs. Briefly, $14.8 \mathrm{mg}$ of curcumin was taken in a vial followed by the addition of $2 \mathrm{~mL}$ of $\mathrm{NaOH}(0.1 \mathrm{M})$ with vigorous mixing for few seconds. Just after the addition of $\mathrm{NaOH}$, the color of the suspension changed to dark red color. Immediately, $36 \mathrm{~mL}$ of $\mathrm{ddH}_{2} \mathrm{O}$ and $2 \mathrm{~mL}$ of $\mathrm{HAuCl}_{4}\left(10^{-2} \mathrm{M}\right)$ were added sequentially, and the solution was allowed to stir vigorously. The reaction suspension was incubated at $27^{\circ} \mathrm{C}$ for $24 \mathrm{~h}$ under constant stirring at $150 \mathrm{rpm}$ to complete the reaction process.

Purification of Curcumin-Conjugated Au QCs. The asobtained suspension was centrifuged at $20000 \mathrm{~g}$ for $15 \mathrm{~min}$ at 0 ${ }^{\circ} \mathrm{C}$ temperature for the separation of $\mathrm{Au}$ QCs from $\mathrm{Au}$ NPs. The as-obtained supernatant was collected and dialyzed for almost 2 days while continuously washing by changing the water at fixed time intervals of $6 \mathrm{~h}$. The pore size cutoff of the benzoylated dialysis tube was $2 \mathrm{kDa}$, which was able to separate the compounds with a molecular weight of $\leq 1200 \mathrm{Da}$ from the compounds with a molecular weight of $>2 \mathrm{kDa}$. Dialysis was performed to separate the unreacted molecules and ions from the $\mathrm{Au}$ QC suspension. After each washing, the samples were collected for the quantification of unbound curcumin molecules.

Quantification of Curcumin Molecules in the Au QC Suspension. The quantification of curcumin molecules in the $\mathrm{Au} \mathrm{QC}$ suspension was done by the following method. First, the UV-vis spectroscopic studies were carried out on the dialyzates collected at various intervals. The characteristic UV peak for curcumin was observed $\sim 265 \mathrm{~nm}$ and assumed not to change on the binding of curcumin to the nanoparticle surface and in the alkaline medium. Second, the different dilutions of curcumin molecules in the alkaline medium were analyzed by UV-vis spectroscopy, and then, plots were made between the absorbance and the concentration. By this linear plot, the curcumin concentration was analyzed in the $\mathrm{Au} \mathrm{QC}$ suspension and in the dialyzate (Figure S1).

Synthesis of Curcumin-Conjugated Au NPs. For the synthesis of curcumin-conjugated $\mathrm{Au}$ NPs, the procedure mentioned by Yang et al. ${ }^{25}$ has been followed with slight modifications. Briefly, $500 \mu \mathrm{L}$ of $20 \mathrm{mM}$ curcumin solution was made in DMSO, and then, $45 \mathrm{~mL}$ of water was added under constant stirring. The $\mathrm{pH}$ of the solution was adjusted to alkaline by the addition of $100 \mu \mathrm{L} \mathrm{NaOH}$. The temperature of the solution was raised to $100{ }^{\circ} \mathrm{C}$, and $\mathrm{HAuCl}_{4}(2.5 \mathrm{~mL}, 10$ $\mathrm{mM}$ ) was added under vigorous stirring for $1 \mathrm{~h}$. After that the mixture was cooled down to room temperature. The dialysis of the as-obtained nanoparticle suspension was performed using a dialysis bag with the pore size of $12 \mathrm{kDa}$ to remove all unreacted impurities and small quantum clusters. The UV-vis spectroscopic analysis of the dialyzate was done to make sure the complete removal of unbound curcumin molecules.

Synthesis of GSH-Conjugated Au QCs. Briefly, $5 \mathrm{~mL}$ of $10^{-2} \mathrm{M} \mathrm{HAuCl}_{4}$ and $10 \mathrm{~mL}$ of $10^{-2} \mathrm{M} \mathrm{GSH}$ were added in a round-bottom flask containing $30 \mathrm{~mL}$ of water with vigorous stirring. Then, $100 \mu \mathrm{L}$ of $\mathrm{NaOH}$ and $5 \mathrm{~mL}$ of $50 \mathrm{mM}$ of $\mathrm{NaBH}_{4}$ were added sequentially. The entire solution was heated at $\sim 70$ ${ }^{\circ} \mathrm{C}$ for $12 \mathrm{~h}$ under vigorous stirring. The dialysis of the asobtained suspension was performed in a benzoylated dialysis bag with the pore size $\sim 2 \mathrm{kDa}$ to remove the unreacted molecules, ions, and impurities.

In Vitro Studies. Cell Culture. The mouse embryo fibroblast cell line (NIH3T3) and breast cancer cell line (MCF7) were cultured in Dulbecco's modified Eagle's medium (DMEM) medium. The detailed procedure is described in our previous article. $^{68}$

Proliferation Assay. The in vitro cell viability was assessed using MTT proliferation assay in NIH3T3 and MCF7 cells. The cells were trypsinized and plated at a density 20000 cells/well in a 96-well plate. After $24 \mathrm{~h}$, the cells were treated with varying concentrations of curcumin, curcumin-conjugated $\mathrm{Au}$ QCs (C-Au QCs), GSH-conjugated Au QCs (GSH-Au $\mathrm{QCs}$ ), and curcumin-conjugated $\mathrm{Au}$ NPs (C-Au NPs); then, the cells were incubated in $5 \% \mathrm{CO}_{2}$ at $37^{\circ} \mathrm{C}$ for $24 \mathrm{~h}$. After the treatment, the medium was removed and $10 \mu \mathrm{L}$ of MTT (10 $\mathrm{mg} / \mathrm{mL}$ ) and $90 \mu \mathrm{L}$ of DMEM were added in each well and further incubated for $4 \mathrm{~h}$ at $37^{\circ} \mathrm{C}$. The formazan crystals were solubilized in isopropanol and the absorbance of MTT was 
measured. More information about this procedure is given in our previous article. ${ }^{68}$

Flow Cytometry. The quantitative measurement of MCF7 cell apoptosis was done by phosphatidylserine exposure on the cell membrane with annexin V. The control cells without treatment and C-Au QC-treated cells were studied. After $24 \mathrm{~h}$, the cells were trypsinized, washed twice with precooled phosphate-buffered saline and incubated with a binding buffer containing annexin V-FITC and PI (BD Biosciences). Flow cytometry analysis was performed using FACSCalibur (Becton Dickinson). The apoptotic cells were defined as both PI positive and annexin V-FITC positive.

Western Blot Analysis. Protein extract from MCF7 cells was obtained in radioimmunoprecipitation assay lysis buffer containing $0.1 \%$ phenylmethylsulfonyl fluoride. The same amount of samples was separated by sodium dodecyl sulfate polyacrylamide gel electrophoresis, transferred, and immobilized on a polyvinylidene difluoride membrane. The membrane was blocked with $5 \%$ nonfat dry milk in Tris-buffered saline containing $0.05 \%$ TWEEN 20 (TBS-T) for $1 \mathrm{~h}$ at room temperature. Appropriate primary antibody was added followed by the incubation of the membranes overnight at $4{ }^{\circ} \mathrm{C}$. Horseradish peroxidase-conjugated rabbit antimouse and goat antirabbit IgG secondary antibody (1:4000) (Bio-Rad) was incubated at room temperature for $1 \mathrm{~h}$. After the final wash, the immunoreactive bands were detected on X-ray films by enhanced chemiluminescence (Thermo Scientific). Data was obtained from three independent experiments.

In Vivo Studies. The groups of six, 6 weeks old female $\mathrm{BALB} / \mathrm{c}$ SCID mice received subcutaneous injections of $1 \times$ $10^{6}$ cells in the dorsal area in a volume of $100 \mu \mathrm{L}$. C-Au QCs were injected intraperitoneally thrice a week and 7 days after the injection of MDA-MB 231 lung cancer cells. Tumor volumes were determined weekly for 6 weeks and calculated on the basis of tumor width $(x)$ and length $(y): x 2 y / 2$, where $x<y$. The major organs (heart, liver, lung, and kidneys) were harvested and fixed in 10\% formalin solution, dehydrated, sliced into $5 \mu \mathrm{m}$ sections, and subjected to hematoxylin and eosin staining. This staining is widely used in histology where hematoxylin gives deep blue-purple color to nucleic acid, whereas eosin provides pink color to the proteins. ${ }^{69}$

Characterization Techniques. The absorbance, photoluminescence, and XPS spectra were recorded using a JASCO (model V570) spectrometer, Cary Eclipse photoluminescence spectrophotometer, and VG Microtech ESCA 3000 instrument, respectively. The TEM images of C-Au NPs, C-Au QCs, and GSH-Au QCs were recorded using a Tecnai G-2 T20 transmission electron microscope and a Tecnai F30 highresolution transmission electron microscope from FEI Inc., respectively. The detailed information of the instruments and sample preparation is described in our previous article. ${ }^{52} \mathrm{~A}$ PALS zeta potential analyzer ver 3.54 (Brookhaven Instruments Corporation) was used to determine the electrophoretic mobilities. The FTIR spectra were obtained using a PerkinElmer Spectrum One instrument. The spectrometer was operated in the \% transmission mode at a resolution of 2 $\mathrm{cm}^{-1}$. To analyze the Au content in C-Au QCs, C-Au NPs, and GSH-Au QCs, they were treated with aquaregia (10\%), until the particles got dissolved, and then, the final volume was adjusted to $10 \mathrm{~mL}$ with deionized water. The Au contents in the samples were measured by ICP-OES spectrometry. More information about the instrument and sample preparation can be found in our previous article. ${ }^{70}$ The mass spectra were collected using a Q Exactive mass spectrometer in the negative ionization mode, controlled by Xcalibur software (Thermo Scientific). The diluted samples were fractionated using an Accela LC system connected to the Q Exactive Orbitrap mass spectrometer (Thermo Scientific) and resolved by a Hypersil GOLD column (Thermo Scientific) over a 10 min gradient (acetonitrile and water with $0.1 \%$ formic acid) with a flow rate of $350 \mu \mathrm{L} \mathrm{min}$. The samples were ionized by a heated electrospray ionization probe. The Orbitrap was set to analyze the survey scans in the mass range $m / z 100-2000$ for curcumin and 1000-10000 for C-Au QCs. The mass spectra were analyzed using the freeware, mMass version 5.5 (Copyright 2005-2016 by Martin Strohalm). ${ }^{71}$

\section{ASSOCIATED CONTENT}

\section{Supporting Information}

The Supporting Information is available free of charge on the ACS Publications website at DOI: 10.1021/acsomega.8b00113. curcumin concentration plot; photoluminescence spectra of curcumin, C-Au NPs, GSH-Au QCs; DLS measurements of C-Au QCs, C-Au NPs, and GSH-Au QCs; DLS measurement of FBS containing media before and after 1 day of adding C-Au QCs; ESI-MS spectra of C-Au QCs and curcumin in DMSO; and normal and cancer cell viability against $\mathrm{C}-\mathrm{Au} \mathrm{NPs}$ and GSH-Au QCs (PDF)

\section{AUTHOR INFORMATION}

\section{Corresponding Author}

*E-mail: p.poddar@ncl.res.in. Phone: +91-20-2590-2580 (Office). Fax: +91-20-2590-2636 (P.P.).

ORCID $\odot$

Puneet Khandelwal: 0000-0001-7204-9397

Pankaj Poddar: 0000-0002-2273-588X

\section{Notes}

The authors declare no competing financial interest.

\section{ACKNOWLEDGMENTS}

P.K., A.A., and A.K.C. acknowledge the Department of Biotechnology (DBT), India, the University Grants Commission of India, and the Council of Scientific \& Industrial Research (CSIR), India, for financial support.

\section{REFERENCES}

(1) Singh, D. K.; Jagannathan, R.; Khandelwal, P.; Abraham, P. M.; Poddar, P. In Situ Synthesis and Surface Functionalization of Gold Nanoparticles with Curcumin and Their Antioxidant Properties: An Experimental and Density Functional Theory Investigation. Nanoscale 2013, 5, 1882-1893.

(2) Shen, L.; Liu, C.-C.; An, C.-Y.; Ji, H.-F. How Does Curcumin Work with Poor Bioavailability? Clues from Experimental and Theoretical Studies. Sci. Rep. 2016, 6, 20872.

(3) Wright, J. S. Predicting the Antioxidant Activity of Curcumin and Curcuminoids. J. Mol. Struct.: THEOCHEM 2002, 591, 207-217.

(4) Bagchi, D.; Chaudhuri, S.; Sardar, S.; Choudhury, S.; Polley, N.; Lemmens, P.; Pal, S. K. Modulation of Stability and Functionality of a Phyto-Antioxidant by Weakly Interacting Metal Ions: Curcumin in Aqueous Solution. RSC Adv. 2015, 5, 102516-102524.

(5) Panchatcharam, M.; Miriyala, S.; Gayathri, V. S.; Suguna, L. Curcumin Improves Wound Healing by Modulating Collagen and Decreasing Reactive Oxygen Species. Mol. Cell. Biochem. 2006, 290, 87-96. 
(6) Maheshwari, R. K.; Singh, A. K.; Gaddipati, J.; Srimal, R. C. Multiple Biological Activities of Curcumin: A Short Review. Life Sci. 2006, 78, 2081-2087.

(7) Loo, C.-Y.; Rohanizadeh, R.; Young, P. M.; Traini, D.; Cavaliere, R.; Whitchurch, C. B.; Lee, W.-H. Combination of Silver Nanoparticles and Curcumin Nanoparticles for Enhanced Anti-Biofilm Activities. J. Agric. Food Chem. 2016, 64, 2513-2522.

(8) El Khoury, E.; Abiad, M.; Kassaify, Z. G.; Patra, D. Green Synthesis of Curcumin Conjugated Nanosilver for the Applications in Nucleic Acid Sensing and Anti-Bacterial Activity. Colloids Surf., B 2015, 127, 274-280.

(9) Moghadamtousi, S. Z.; Kadir, H. A.; Hassandarvish, P.; Tajik, H.; Abubakar, S.; Zandi, K. A Review on Antibacterial, Antiviral, and Antifungal Activity of Curcumin. BioMed Res. Int. 2014, 2014, 186864. (10) Tyagi, P.; Singh, M.; Kumari, H.; Kumari, A.; Mukhopadhyay, K. Bactericidal Activity of Curcumin I Is Associated with Damaging of Bacterial Membrane. PLoS One 2015, 10, e0121313.

(11) Gao, X.; Zheng, F.; Guo, G.; Liu, X.; Fan, R.; Qian, Z.-y.; Huang, N.; Wei, Y.-q. Improving the Anti-Colon Cancer Activity of Curcumin with Biodegradable Nano-Micelles. J. Mater. Chem. B 2013, 1, 5778.

(12) Valentini, A.; Conforti, F.; Crispini, A.; De Martino, A.; Condello, R.; Stellitano, C.; Rotilio, G.; Ghedini, M.; Federici, G.; Bernardini, S.; Pucci, D. Synthesis, Oxidant Properties, and Antitumoral Effects of a Heteroleptic Palladium(II) Complex of Curcumin on Human Prostate Cancer Cells. J. Med. Chem. 2009, 52, 484-491.

(13) Peng, S.-F.; Lee, C.-Y.; Hour, M.-J.; Tsai, S.-C.; Kuo, D.-H.; Chen, F.-A.; Shieh, P.-C.; Yang, J.-S. Curcumin-Loaded Nanoparticles Enhance Apoptotic Cell Death of U2OS Human Osteosarcoma Cells through the Akt-Bad Signaling Pathway. Int. J. Oncol. 2014, 44, 238246.

(14) Hatamie, S.; Akhavan, O.; Sadrnezhaad, S. K.; Ahadian, M. M.; Shirolkar, M. M.; Wang, H. Q. Curcumin-Reduced Graphene Oxide Sheets and Their Effects on Human Breast Cancer Cells. Mater. Sci. Eng., C 2015, 55, 482-489.

(15) Chen, C.-C.; Sureshbabul, M.; Chen, H.-W.; Lin, Y.-S.; Lee, J.Y.; Hong, Q.-S.; Yang, Y.-C.; Yu, S.-L. Curcumin Suppresses Metastasis via Sp-1, FAK Inhibition, and E-Cadherin Upregulation in Colorectal Cancer. Evidence-Based Complementary Altern. Med. 2013, 2013, 1-17.

(16) Begum, A. N.; Jones, M. R.; Lim, G. P.; Morihara, T.; Kim, P.; Heath, D. D.; Rock, C. L.; Pruitt, M. A.; Yang, F.; Hudspeth, B.; Hu, S.; Faull, K. F.; Teter, B.; Cole, G. M.; Frautschy, S. A. Curcumin Structure-Function, Bioavailability, and Efficacy in Models of Neuroinflammation and Alzheimer's Disease. J. Pharmacol. Exp. Ther. 2008, 326, 196-208.

(17) Mathew, A.; Fukuda, T.; Nagaoka, Y.; Hasumura, T.; Morimoto, H.; Yoshida, Y.; Maekawa, T.; Venugopal, K.; Kumar, D. S. Curcumin Loaded-PLGA Nanoparticles Conjugated with Tet-1 Peptide for Potential Use in Alzheimer's Disease. PLoS One 2012, 7, e32616.

(18) Tiwari, S. K.; Agarwal, S.; Seth, B.; Yadav, A.; Nair, S.; Bhatnagar, P.; Karmakar, M.; Kumari, M.; Chauhan, L. K. S.; Patel, D. K.; Srivastava, V.; Singh, D.; Gupta, S. K.; Tripathi, A.; Chaturvedi, R. K.; Gupta, K. C. Curcumin-Loaded Nanoparticles Potently Induce Adult Neurogenesis and Reverse Cognitive Deficits in Alzheimer's Disease Model via Canonical Wnt/beta-Catenin Pathway. ACS Nano 2014, 8, 76-103.

(19) Palmal, S.; Maity, A. R.; Singh, B. K.; Basu, S.; Jana, N. R.; Jana, N. R. Inhibition of Amyloid Fibril Growth and Dissolution of Amyloid Fibrils by Curcumin-Gold Nanoparticles. Chem.-Eur. J. 2014, 20, 6184-6191.

(20) Yang, F.; Lim, G. P.; Begum, A. N.; Ubeda, O. J.; Simmons, M. R.; Ambegaokar, S. S.; Chen, P. P.; Kayed, R.; Glabe, C. G.; Frautschy, S. A.; Cole, G. M. Curcumin Inhibits Formation of Amyloid Oligomers and Fibrils, Binds Plaques, and Reduces Amyloid in Vivo. J. Biol. Chem. 2005, 280, 5892-5901.

(21) Ramassamy, C. Emerging Role of Polyphenolic Compounds in the Treatment of Neurodegenerative Diseases: A Review of Their Intracellular Targets. Eur. J. Pharmacol. 2006, 545, 51-64.
(22) Cui, L.; Miao, J.; Cui, L. Cytotoxic Effect of Curcumin on Malaria Parasite Plasmodium Falciparum: Inhibition of Histone Acetylation and Generation of Reactive Oxygen Species. Antimicrob. Agents Chemother. 2007, 51, 488-494.

(23) Chakrabarti, R.; Rawat, P. S.; Cooke, B. M.; Coppel, R. L.; Patankar, S. Cellular Effects of Curcumin on Plasmodium Falciparum Include Disruption of Microtubules. PLoS One 2013, 8, e57302.

(24) Mathuria, N.; Verma, R. J. Ameliorative Effect of Curcumin on Aflatoxin-Induced Toxicity in Serum of Mice. Acta Pol. Pharm. 2008, $65,339-343$.

(25) Yang, X. X.; Li, C. M.; Huang, C. Z. Curcumin Modified Silver Nanoparticles for Highly Efficient Inhibition of Respiratory Syncytial Virus Infection. Nanoscale 2016, 8, 3040-3048.

(26) Price, L. C.; Buescher, R. W. Kinetics of Alkaline Degradation of the Food Pigments Curcumin and Curcuminoids. J. Food Sci. 1997, 62, 267-269.

(27) Jagannathan, R.; Abraham, P. M.; Poddar, P. TemperatureDependent Spectroscopic Evidences of Curcumin in Aqueous Medium: A Mechanistic Study of Its Solubility and Stability. J. Phys. Chem. B 2012, 116, 14533-14540.

(28) Batkulwar, K. B.; Jana, A. K.; Godbole, R. K.; Khandelwal, P.; Sengupta, N.; Kulkarni, M. J. Hydralazine Inhibits Amyloid Beta (A $\beta)$ Aggregation and Glycation and Ameliorates $\mathrm{A} \beta$ 1-42 Induced Neurotoxicity. RSC Adv. 2016, 6, 108768-108776.

(29) Sharma, N.; Sivalingam, V.; Maurya, S.; Prasad, A.; Khandelwal, P.; Yadav, S. C.; Patel, B. K. New Insights into in Vitro Amyloidogenic Properties of Human Serum Albumin Suggest Considerations for Therapeutic Precautions. FEBS Lett. 2015, 589, 4033-4038.

(30) Gorantla, N. V.; Khandelwal, P.; Poddar, P.; Chinnathambi, S. Global Conformation of Tau Protein Mapped by Raman Spectroscopy. In Tau Protein: Methods and Protocols; Smet-Nocca, C., Ed.; Methods in Molecular Biology; Springer New York: New York, NY, 2017; Vol. 41, pp 21-31.

(31) Yallapu, M. M.; Khan, S.; Maher, D. M.; Ebeling, M. C.; Sundram, V.; Chauhan, N.; Ganju, A.; Balakrishna, S.; Gupta, B. K.; Zafar, N.; Jaggi, M.; Chauhan, S. C. Anti-Cancer Activity of Curcumin Loaded Nanoparticles in Prostate Cancer. Biomaterials 2014, 35, $8635-8648$.

(32) Verderio, P.; Bonetti, P.; Colombo, M.; Pandolfi, L.; Prosperi, D. Intracellular Drug Release from Curcumin-Loaded PLGA Nanoparticles Induces G2/M Block in Breast Cancer Cells. Biomacromolecules 2013, 14, 672-682.

(33) Kotcherlakota, R.; Barui, A. K.; Prashar, S.; Fajardo, M.; Briones, D.; Rodríguez-Diéguez, A.; Patra, C. R.; Gómez-Ruiz, S. Curcumin Loaded Mesoporous Silica: An Effective Drug Delivery System for Cancer Treatment. Biomater. Sci. 2016, 4, 448-459.

(34) Jambhrunkar, S.; Karmakar, S.; Popat, A.; Yu, M.; Yu, C. Mesoporous Silica Nanoparticles Enhance the Cytotoxicity of Curcumin. RSC Adv. 2014, 4, 709-712.

(35) Mathew, A.; Aravind, A.; Brahatheeswaran, D.; Fukuda, T.; Nagaoka, Y.; Hasumura, T.; Iwai, S.; Morimoto, H.; Yoshida, Y.; Maekawa, T.; Venugopal, K.; Sakthi Kumar, D. Amyloid-Binding Aptamer Conjugated Curcumin-PLGA Nanoparticle for Potential Use in Alzheimer's Disease. BioNanoScience 2012, 2, 83-93.

(36) Jin, R. Quantum Sized, Thiolate-Protected Gold Nanoclusters. Nanoscale 2010, 2, 343-362.

(37) Price, R. C.; Whetten, R. L. All-Aromatic, Nanometer-Scale, Gold-Cluster Thiolate Complexes. J. Am. Chem. Soc. 2005, 127, 13750-13751.

(38) Zhang, L.; Wang, E. Metal Nanoclusters: New Fluorescent Probes for Sensors and Bioimaging. Nano Today 2014, 9, 132-157.

(39) Khandelwal, P.; Singh, D. K.; Poddar, P. One Pot Process for the Preparation of Gold Quantum Clusters. U.S. Patent 9,857,376 B2, 2018.

(40) Sindhu, K.; Rajaram, A.; Sreeram, K. J.; Rajaram, R. Curcumin Conjugated Gold Nanoparticle Synthesis and Its Biocompatibility. RSC Adv. 2014, 4, 1-11. 
(41) Dey, S.; Sreenivasan, K. Conjugating Curcumin to Water Soluble Polymer Stabilized Gold Nanoparticles via $\mathrm{pH}$ Responsive Succinate Linker. J. Mater. Chem. B 2015, 3, 824-833.

(42) Heo, D. N.; Ko, W.-K.; Moon, H.-J.; Kim, H.-J.; Lee, S. J.; Lee, J. B.; Bae, M. S.; Yi, J.-K.; Hwang, Y.-S.; Bang, J. B.; Kim, E.-C.; Do, S. H.; Kwon, I. K. Inhibition of Osteoclast Differentiation by Gold Nanoparticles Functionalized with Cyclodextrin Curcumin Complexes. ACS Nano 2014, 8, 12049-12062.

(43) Khandelwal, P.; Poddar, P. Fluorescent Metal Quantum Clusters: An Updated Overview of the Synthesis, Properties, and Biological Applications. J. Mater. Chem. B 2017, 5, 9055-9084.

(44) Chen, T.; Hu, Y.; Cen, Y.; Chu, X.; Lu, Y. A Dual-Emission Fluorescent Nanocomplex of Gold-Cluster-Decorated Silica Particles for Live Cell Imaging of Highly Reactive Oxygen Species. J. Am. Chem. Soc. 2013, 135, 11595-11602.

(45) Link, S.; Beeby, A.; FitzGerald, S.; El-Sayed, M. A.; Schaaff, T. G.; Whetten, R. L. Visible to Infrared Luminescence from a 28-Atom Gold Cluster. J. Phys. Chem. B 2002, 106, 3410-3415.

(46) Baksi, A.; Xavier, P. L.; Chaudhari, K.; Goswami, N.; Pal, S. K.; Pradeep, T. Protein-Encapsulated Gold Cluster Aggregates: The Case of Lysozyme. Nanoscale 2013, 5, 2009.

(47) Wang, Y.; Chen, J.-T.; Yan, X.-P. Fabrication of Transferrin Functionalized Gold Nanoclusters/Graphene Oxide Nanocomposite for Turn-On Near-Infrared Fluorescent Bioimaging of Cancer Cells and Small Animals. Anal. Chem. 2013, 85, 2529-2535.

(48) Xavier, P. L.; Chaudhari, K.; Verma, P. K.; Pal, S. K.; Pradeep, T. Luminescent Quantum Clusters of Gold in Transferrin Family Protein, Lactoferrin Exhibiting FRET. Nanoscale 2010, 2, 2769-2776.

(49) Nair, L. V.; Nazeer, S. S.; Jayasree, R. S.; Ajayaghosh, A. Fluorescence Imaging Assisted Photodynamic Therapy Using Photosensitizer-Linked Gold Quantum Clusters. ACS Nano 2015, 9, 58255832.

(50) Hussain, A. M. P.; Sarangi, S. N.; Kesarwani, J. A.; Sahu, S. N. Au-Nanocluster Emission Based Glucose Sensing. Biosens. Bioelectron. 2011, 29, 60-65.

(51) Khandelwal, P.; Singh, D. K.; Sadhu, S.; Poddar, P. Modulation of Reaction Kinetics for the Tuneable Synthesis of Gold Nanoparticles and Quantum Clusters: Application of Gold Quantum Clusters as “Turn-Off” Sensing Probe for Sn 4+ Ions. ChemPlusChem 2014, 79, 134-142.

(52) Khandelwal, P.; Singh, D. K.; Sadhu, S.; Poddar, P. Study of the Nucleation and Growth of Antibiotic Labeled Au NPs and Blue Luminescent Au 8 Quantum Clusters for $\mathrm{Hg} 2+$ Ion Sensing, Cellular Imaging and Antibacterial Applications. Nanoscale 2015, 7, 1998520002.

(53) Samanta, A.; Dhar, B. B.; Devi, R. N. Ultrasmall Gold Cluster Arrays Encapsulated in Silica Nanospheres: Applications in Fluorescence Imaging and Catalysis. J. Phys. Chem. C 2012, 116, 17481754.

(54) Gao, Y.; Shao, N.; Pei, Y.; Zeng, X. C. Icosahedral Crown Gold Nanocluster $\mathrm{Au} 43 \mathrm{Cu} 12$ with High Catalytic Activity. Nano Lett. 2010, 10, 1055-1062.

(55) Wang, Z. W.; Palmer, R. E. Experimental Evidence for Fluctuating, Chiral-Type Au55 Clusters by Direct Atomic Imaging. Nano Lett. 2012, 12, 5510-5514.

(56) Wang, H.-H.; Lin, C.-A. J.; Lee, C.-H.; Lin, Y.-C.; Tseng, Y.-M.; Hsieh, C.-L.; Chen, C.-H.; Tsai, C.-H.; Hsieh, C.-L.; Shen, J.-L.; Chan, W.-H.; Chang, W.-H.; Yeh, H.-I. Fluorescent Gold Nanoclusters as a Biocompatible Marker for in Vitro and in Vivo Tracking of Endothelial Cells. ACS Nano 2011, 5, 4337-4344.

(57) Huang, P.; Lin, J.; Wang, S.; Zhou, Z.; Li, Z.; Wang, Z.; Zhang, C.; Yue, X.; Niu, G.; Yang, M.; Cui, D.; Chen, X. PhotosensitizerConjugated Silica-Coated Gold Nanoclusters for Fluorescence Imaging-Guided Photodynamic Therapy. Biomaterials 2013, 34, 4643-4654.

(58) Zhang, X.-D.; Chen, J.; Yang, J.; Wang, J.-Y.; Shen, X.; Song, S.S.; Wang, H.; He, H.; Wang, X.; Fan, S.; Sun, Y.-M.; Guo, M. Use of Epidermal Growth Factor Receptor Antibody-Gold Cluster Con- jugates with Good Renal Excretion in Targeted Cancer Radiation Treatment. J. Mater. Chem. B 2015, 3, 4735-4741.

(59) Khandelia, R.; Bhandari, S.; Pan, U. N.; Ghosh, S. S.; Chattopadhyay, A. Gold Nanocluster Embedded Albumin Nanoparticles for Two-Photon Imaging of Cancer Cells Accompanying Drug Delivery. Small 2015, 11, 4075-4081.

(60) Zhou, F.; Feng, B.; Yu, H.; Wang, D.; Wang, T.; Liu, J.; Meng, Q.; Wang, S.; Zhang, P.; Zhang, Z.; Li, Y. Cisplatin ProdrugConjugated Gold Nanocluster for Fluorescence Imaging and Targeted Therapy of the Breast Cancer. Theranostics 2016, 6, 679-687.

(61) Chen, D.; Li, B.; Cai, S.; Wang, P.; Peng, S.; Sheng, Y.; He, Y.; Gu, Y.; Chen, H. Dual Targeting Luminescent Gold Nanoclusters for Tumor Imaging and Deep Tissue Therapy. Biomaterials 2016, 100, 116.

(62) Chen, W.-Y.; Lin, J.-Y.; Chen, W.-Y.; Luo, L.; Wei-Guang Diau, E.; Chen, Y.-C. Functional Gold Nanoclusters as Antimicrobial Agents for Antibiotic-Resistant Bacteria. Nanomedicine 2010, 5, 755-764.

(63) Liu, C.-L.; Wu, H.-T.; Hsiao, Y.-H.; Lai, C.-W.; Shih, C.-W.; Peng, Y.-K.; Tang, K.-C.; Chang, H.-W.; Chien, Y.-C.; Hsiao, J.-K.; Cheng, J.-T.; Chou, P.-T. Insulin-Directed Synthesis of Fluorescent Gold Nanoclusters: Preservation of Insulin Bioactivity and Versatility in Cell Imaging. Angew. Chem., Int. Ed. 2011, 50, 7056-7060.

(64) Nair, L. V.; Philips, D. S.; Jayasree, R. S.; Ajayaghosh, A. A nearInfrared Fluorescent Nanosensor (AuC@Urease) for the Selective Detection of Blood Urea. Small 2013, 9, 2673-2677.

(65) Govindaraju, S.; Rengaraj, A.; Arivazhagan, R.; Huh, Y.-S.; Yun, K. Curcumin-Conjugated Gold Clusters for Bioimaging and Anticancer Applications. Bioconjugate Chem. 2018, 29, 363-370.

(66) Luo, Z.; Yuan, X.; Yu, Y.; Zhang, Q.; Leong, D. T.; Lee, J. Y.; $\mathrm{Xie}, \mathrm{J}$. From Aggregation-Induced Emission of $\mathrm{Au}(\mathrm{I})$-Thiolate Complexes to Ultrabright $\mathrm{Au}(0) @ \mathrm{Au}(\mathrm{I})-$ Thiolate Core-Shell Nanoclusters. J. Am. Chem. Soc. 2012, 134, 16662-16670.

(67) Zhang, C.; Li, C.; Liu, Y.; Zhang, J.; Bao, C.; Liang, S.; Wang, Q.; Yang, Y.; Fu, H.; Wang, K.; Cui, D. Gold Nanoclusters-Based Nanoprobes for Simultaneous Fluorescence Imaging and Targeted Photodynamic Therapy with Superior Penetration and Retention Behavior in Tumors. Adv. Funct. Mater. 2015, 25, 1314-1325.

(68) Padhye, P.; Alam, A.; Ghorai, S.; Chattopadhyay, S.; Poddar, P. Doxorubicin-Conjugated $\beta$-NaYF 4:Gd 3+/Tb 3+ Multifunctional, Phosphor Nanorods: A Multi-Modal, Luminescent, Magnetic Probe for Simultaneous Optical and Magnetic Resonance Imaging and an Excellent pH-Triggered Anti-Cancer Drug Delivery Nanovehicle. Nanoscale 2015, 7, 19501-19518.

(69) Fischer, A. H.; Jacobson, K. A.; Rose, J.; Zeller, R. Hematoxylin and Eosin Staining of Tissue and Cell Sections. Cold Spring Harb. Protoc. 2008, pdb.prot 4986.

(70) Sharan, C.; Khandelwal, P.; Poddar, P. Biomilling of RodShaped ZnO Nanoparticles: A Potential Role of Saccharomyces Cerevisiae Extracellular Proteins. RSC Adv. 2015, 5, 1883-1889.

(71) Strohalm, M.; Kavan, D.; Novák, P.; Volný, M.; Havlíček, V. mMass 3: A Cross-Platform Software Environment for Precise Analysis of Mass Spectrometric Data. Anal. Chem. 2010, 82, 46484651. 